\title{
TILLING: THE MODERN TECHNOLOGY IN «REVERSE» GENETIC OF PLANTS \\ (review)
}

\section{A.S. SULIMA, V.A. ZHUKOV}

All-Russian Research Institute for Agricultural Microbiology, Federal Agency of Scientific Organizations, 3, sh. Podbel'skogo, St. Petersburg, 196608 Russia, e-mail sulan555@mail.ru

Acknowledgements:

Authors are thankful to A.Yu. Borisov (ARRIAM, St. Petersburg) for the discussions that generated the interest in the TILLING method.

Supported by Russian Foundation for Fundamental Research (grants 14-04-32289-mol a and 14-04-01442-a)

Received March 30, 2015

\section{Abstract}

There are two basic approaches in genetic studies called «forward» and «reverse» genetics. While the «forward» genetics studies the inheritance of traits (phenotype) in living organisms and identifies genetic factors that influence the expression of these traits (working on the principle of «from phenotype to genotype»), the «reverse» genetics reveals the function of gene by changing its structure or activity with subsequent analysis of the associated changes in phenotype (the «from genotype to phenotype» principle). With the development of large-scale genomic sequencing technologies the «reverse» genetics received substantial support, taking the leading position both in scientific and applied fields. Basic principles underlying the novel method of «reverse» genetics called TILLING (for Targeting Induced Local Lesions IN Genomes) are reviewed in this paper. TILLING combines the classic mutation analysis with modern approaches to detecting the nucleotide substitutions in a target locus in genome. The method is highly effective and is applicable to a wide range of biological objects, thereby winning a world-wide recognition. The key stages of preparation for TILLING analysis are described: obtaining of mutagenized population and development of TILLING platform, which includes the organized collection of mutants and database with information about the collection. The main approaches to the detection of point mutations currently used worldwide, including new approaches based on NGS methods (Next Generation Sequencing), are presented. The technical requirements crucial for the successful conducting of TILLING-analysis, as well as variations and modifications of existing techniques designed to solve various scientific tasks, are highlighted. The results obtained using the TILLING method by the group of authors in their research of specificity of partners recognition during the development of mutualistic symbiosis between the garden pea (Pisum sativum L.) and nodule bacteria Rhizobium leguminosarum bv. viciae are also presented. Authors were able to identify a number of mutants in pea receptor kinase gene $L y k X$, which is the most likely candidate for the determinant of plant's increased selectivity toward bacterial microsymbionts. Further study of obtained mutants will help to reveal the function of $L y k X$ and its role in symbiosis between pea and nodule bacteria

Keywords: plant genetics, «reverse» genetics, TILLING, detection of mutations, pea, «Afghan» phenotype.

Modern genetics has entered a «post-genomics era» [1-3], when the information about genome structure became available for a wide range of biological objects. Under these conditions, the identification of the biological function of genes with known sequences is of particular importance. A technique of TILLING based on a combination of features and approaches of «forward» and «reverse» genetics is one of the most successful methods for solving this problem.

«Forward» and «reverse» genetics in plant studies. Ever since the discovery of Gregor Mendel (1865) [4], classic, or «forward» genetics has been studying the inheritance of traits (phenotype) in a number of generations of living organisms. With phenotype as a starting point, «forward» genetics reveals genetic factors that influence the expression of traits. Thus, «forward»ge- 
netics works on the principle of «from phenotype to genotype». One of the key steps of the experimental application of this approach is provision of extensive mutagenized populations for further research of the phenotypic changes of interest. For decades, large collections of mutants were created for a plurality of model plant objects, in particular for Arabidopsis thaliana (L.) Heynh., Medicago truncatula Gaertn., Solanum lycopersicum L., Zea mais L. et al., the analysis of which identified a number of genes controlling plant development [5].

Since the 1980s, the knowledge accumulated within the previous period (discovery of DNA as the carrier of genetic information, deciphering genetic code, development of methods of sequencing and genome modification) [6] opened a new approach involving the analysis of not phenotype and its genetic control, but the very DNA sequence and the effects caused by its changes (mutations). This concept was called «reverse» genetics [7, 8].

The object of the «reverse» genetics study is usually a gene of unknown function, detected by EST (Expressed Sequence Tag), complete genome or its single site, etc. sequencing. The research strategy is to change the structure or activity of such gene with subsequent analysis of the associated phenotype changes. With the development of large-scale genomic sequencing technologies the «reverse» genetics received substantial support, taking the leading position both in scientific and applied fields. Currently there are several techniques of targeted mutagenesis (using T-DNA, transposons/retrotransposon, RNA-silencing CRISPR-Cas system) [9-16], but their use is usually limited to model objects with small genomes, such as arabidopsis ( $A$. thaliana), rice (Oryza sativa L.), and alfalfa (M. truncatula).

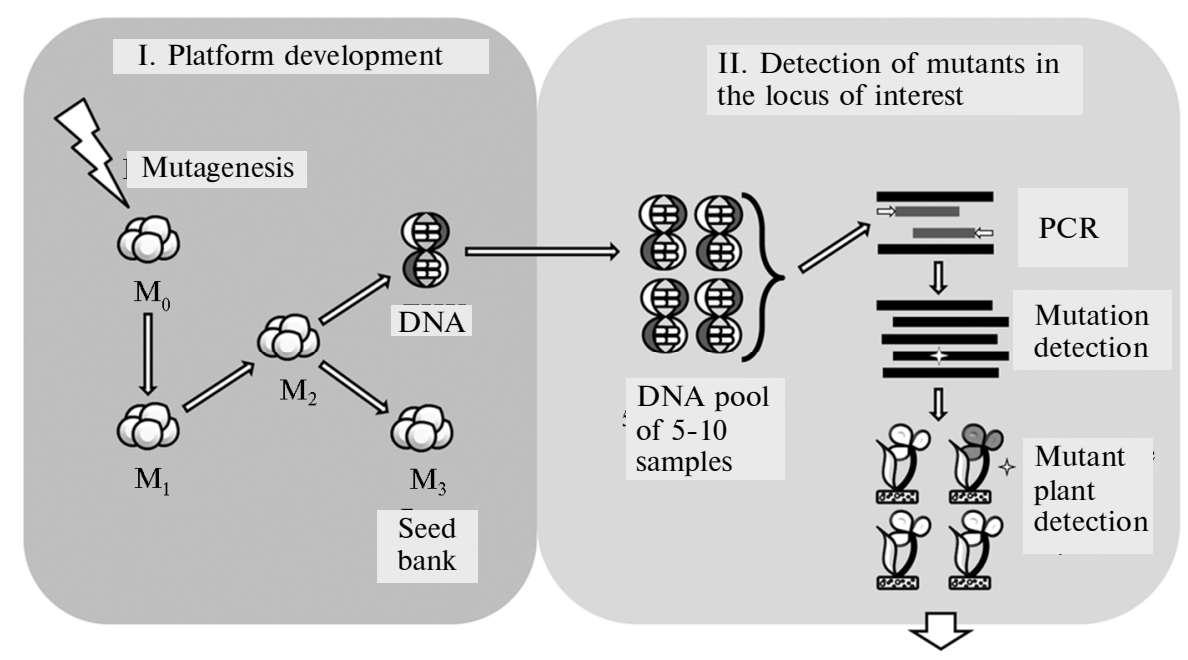

III. Phenotype analysis in mutants

General scheme of procedures for identifying plant mutants using TILLING method (Targeting Induced Local Lesions in Genomes): $\mathrm{M}_{0}-\mathrm{M}_{3}-$ mutant generations $\left(\mathrm{M}_{0}-\right.$ original mutagenized population). DNA pool is the result of blending of DNA samples isolated from a number (5 to 10) of mutant plants. Please find details in the article text.

The TILLING (Targeting Induced Local Lesions in Genomes) method was developed about 15 years ago as an alternative for targeted mutagenesis [17] and is now gaining ground. It combines classical mutagenesis and precise detection of polymorphic sites within the known nucleotide sequence (Fig.). The main advantage of TILLING «reverse» genetics approach is its applicability to almost any plant object, regardless of the genome size, ploidy, and type of reproduction $[17,18]$. TILLING is developing rapidly. Thus, better methods for 
detecting nucleotide substitutions in mutagenized populations are developed, and bioinformatic tools to process the results are created. Research centers that provide TILLING platforms for fundamental and applied research arise. Along with this, there appear specific modifications of the method, designed to address a wide range of tasks, such as EcoTILLING and De-TILLING which will be discussed below.

TILLING method: development of TILLING platform. Creation of a collection of mutant object of interest is an important initial step. As a rule, preference is given to chemical mutagenesis proven in the classical genetics studies. It provides high incidence of various point mutations distributed in the genome randomly. Analysis of 192 A. thaliana genes after ethylmethane sulfonate (ethylmethane sulphonate, EMS) treatment in a sample of $3,000 \mathrm{M}_{2}$ plants demonstrated the frequency of nucleotide substitutions of approximately 10 per gene [19]. Each $\mathrm{M}_{2}$ plant has the average of 720 mutations [18], while insertional mutagenesis using Agrobacterium gives just about 1.5 T-DNA insertions per one mutant line [20]. So, with chemical mutagens, much smaller populations can be used, thus speeding up and simplifying research. Another significant advantage of chemical mutagenesis is the possibility of its use to obtain a wide range of mutations, including missense mutations (amino acid substitution in the encoded protein), nonsense-mutations (early appearance of a stop codon, causing the synthesis of a truncated protein) and damages of splice sites. This makes it possible to create a number of different alleles of the gene of interest (locus), including alleles with function acquisition and hypomorphic (causing a weakened trait expression) alleles [9]. Finally, mutations caused by chemical agents are stable in a number of successive generations, which is not always true for alternative methods of mutagenesis $[5,21]$.

Among mutagens used in plant genetics, two agents of similar action, EMS and N-nitroso-N-methylurea (1-methyl-1-nitrosourea, MNU), are the most common ones. Both compounds cause alkylation of bases, especially guanine $(\mathrm{G})$, thereby breaking DNA strand complementary. Alkylated guanine interacts not with cytosine (C) but with thymine $(\mathrm{T})$, which causes a transition when the G-C pair is replaced with A-T as a result of DNA replication [22]. Sodium azide with even higher frequency of mutation induction than in EMS (i.e., an average of one mutation per $374 \mathrm{~kb}$ compared to one mutation per 1 $\mathrm{Mb}$ in EMS) was also used [23, 24]. However, the use of sodium azide is limited by the fact that this substance exhibits strong mutagenic properties only in certain organisms, such as Escherichia coli, Saccharomyces cerevisiae, Hordeum vulgare L., O. sativa [25].

Fast neutron bombardment resulting in a large number of deletions is used for De-TILLING (Deletion TILLING) [26] instead of chemical mutagenesis. Using this approach, it is possible, in particular, to «knock» tandemly repeated genes which are widely represented in plants [27-29]. The De-TILLING method is well suited for improving the quality of agricultural varieties, as it is characterized by low frequency of background mutations [26].

Converting a collection of mutants into a platform for TILLING-analysis involves the preparation of $\mathrm{M}_{2}$ generation plants, collection of DNA samples and seeds, and creation of a database. The ready-to-use TILLING platform may, of course, be a resource used for the purposes of both «reverse» and «forward» genetics (to identify mutants with phenotypes of interest).

Most existing TILLING platforms contain from 3 to 5 thousand samples, although in some cases this number may be up to 10 thousand [30]. Usually, to create a platform, $\mathrm{M}_{2}$ and $\mathrm{M}_{3}$ plant phenotypes are described in de- 
tail which makes it possible to pre-enriched the sample analyzed with the specimens of desired properties. The study of the genes controlling nitrogenfixing symbiosis in a lotus Japanese Lotus japonicus (Regel.) K. Larsen conducted by J.A. Perry et al. [31] in which preliminary selection of mutants with damaged symbiotic nodule formation, is an example of the successful use of this approach.

All information about the TILLING platform is entered in the database, which is usually placed in the public domain on the Internet. The database is based on the phenotypic description of the collection performed individually for each mutant line at all stages of plant development. For convenience, this information is organized in hierarchical groups, and is additionally illustrated with photographic materials in some cases. Some databases also contain information on the currently analyzed genes and their mutations detected, but often this information is closed due to its commercial value.

Despite the fact that the analysis of mutants using TILLING method can significantly simplify the study of gene function, preparing the platform for its implementation is a long and laborious process. To date, some major research centers provide access to TILLING platforms developed for widely studied plant species: M. truncatula, L. japonicus, and Brassica rapa L. in John Innes Centre (Great Britain) (RevGenUK) [32]; Pisum sativum L., S. lycopersicum, Capsicum annum L., Cucumis sativus L., and Cucumis melo L. in the National Institute for Agriculrural Research (INRA, France) (UTILLdb) [33]; O. sativa, $S$. lycopersicum, and A. thaliana in the University of California(USA) [34]; Z. mays in Pudue University (USA); Glycine $\max$ (L.) Merr. in Southern Illinois University (USA); Avena sativa L. in CropTailor AB (Switzerland) [35]; A. thaliana, Brassica oleracea L., and Brasica napus L. in the University of British Columbia (Canada) (CAN-TILL) (36]; H. vulgare in the Department of agri-environmental Sciences and Technologies (DiSTA) of the University of Bologna (Italy) (TILLMore) [23].

Methods for detecting mutations. TILLING analysis is based on highly accurate detection of mutations within a particular area of interest. Since the method introduction in 2000 [17], a number of approaches to this problem were developed sequentially, each of the methods being less expensive and more effective compared to previous ones. The initial stages of material preparation (DNA isolation from plant mutants collection, combining DNA pools of 8-10 samples and amplification of the target site using specially constructed DNA primers) are similar in all strategies (see. Fig.). Before the advent of NGS technologies (see below), all detection methods were anyway based on the principle of heteroduplex formation using double-stranded DNA melting and subsequent annealing of heteroallelic fragments.

In the first described application of the method of TILLING [17], denaturing high-performance liquid chromatography (DHPLC) was used to identify mutants, which at that time was the most sensitive method for comparing amplified DNA fragments. DHPLC is an ion-pair reversed-phase liquid chromatography on alkylated nonporous particles [37] and is able to separate DNA homo- and heteroduplexes under partial denaturation. Despite its high resolution, the procedure duration and the high cost limited the use of DHPLC in large-scale studies. The first step to cost reduction and improvement of the TILLING process automation was the replacement of DHPLC by cleavage of heteroduplexes with specific endonucleases followed by products electrophoresis in polyacrylamide gel and visualization using a highly sensitive gel assay system of LI-COR [38]. For the above method, endonucleass specific for singlestranded DNA, such as Aspergillus oryzae S1 nuclease, Penicillium citrinum P1 
and Vigna radiata (L.) R. Wilczek mung bean seedling nuclease were used [21]. The general disadvantage of all the above enzymes is the need to maintain an acidic $\mathrm{pH}(\sim 5)$ for their optimal performance. At such $\mathrm{pH}$ values, the DNA strand can unravel in AT-rich sites, which results in its non-specific cleavage. Endonuclease CEL1, isolated from celery (Apium graveolens L.) [39], in contrast, demonstrates optimum performance at neutral $\mathrm{pH}$, which made it the most popular enzyme for TILLING analysis. Furthermore, crude celery juice extract was shown to have not less enzymatic activity compared to expensive purified CEL1 [40].

Alternatively to CEL1, ENDO-1 endonuclease of the S1 family found in Arabidopsis may be used; ENDO-1 is capable of effective functioning at $\mathrm{pH}=7.5$ and is of high specificity [41]. ENDO-1 has been used in TILLING analysis in pea ( $P$. sativum) $[41,42]$, tomato (S. lycopersicum) $(43)$, and in EcoTILLING (TILLING technique used in natural populations to study the variability of specific loci) in $A$. thaliana [42].

Use of NGS technologies for TILLING. High performance NGS (Next Generation Sequencing) methods allowing analyzing millions of DNA sequences in a single experiment have been widely distributed in molecular genetics within the last 10 years [44, 45]. Due to NGS, sequencing of full genomes in model and practically valuable organisms became possible. In TILLING analysis, NGS is used as a fast and reliable method for detecting mutations, not requiring any preliminary procedures in addition to the amplification of the desired fragment.

Available modern NGS platforms include 454-FLX genome sequencer and its smaller version GS Junior, operating according to the principle of pyrosequencing (Roche Applied Science, Germany), HiSeq and HiSeqX systems based on the method of sequencing by synthesis (Illumina, Inc., USA), SOLiD system (Applied Biosystems, USA), and others. Relatively high costs of equipment and reagents, and the difficulties associated with data array processing using bioinformatics methods remain the most serious obstacles in the implementation of NGS technology. Nevertheless, NGS is gradually replacing the outdated screening methods based on endonuclease splitting; NGS is currently used by such major scientific centers such as UC Davis Genome Center at the University of California (USA) and the Unité de Recherche en Génomique Végétale (URGV) at the National Institute for Agricultural Research (INRA, France).

Use of TILLING to study symbiotic specificity control in peas. The advantages of TILLING were evaluated by the authors of this review in the study of the control of specificity of pea (P. sativum L.) interaction with endosymbiotic rhizobia Rhizobium leguminosarum bv. viciae. In legumes (Fabaceae) which include pea, LysM-RLK proteins (LysM-receptor-like kinase) are known to play an important role in the recognition of bacterial symbionts [46-48]. Due to these proteins, plants can distinguish «their own» symbionts among the pool of soil microorganisms, focusing on the specific structure of their signaling molecule, the Nod-factor (nodulation factor). In this case, the receptor and the ligand operate on the «key-lock» principle, and bacteria gain access to the host cell only if their molecular «key» fits.

The legume-Rhizobium interaction specificity limit is generally at the species level. However, within pea species, a contrast group of genotypes with increased selectivity for microsymbionts can be distinguished. For successful recognition of rhizobia by the representatives of this group, a special modification of Nod-factor (double acetylation) is required, which is of no importance for all other pea varieties. This trait first described over 80 years ago in plants originat- 
ing from West Asia Minor was named the Afghan phenotype [49].

The gene determining the Afghan phenotype was named Sym2 [50] and mapped to pea genome linkage group I [51]. The nature, Sym2 nucleotide sequence and its protein product function are still unknown. Based on the existence of Afghan phenotype the Sym2 protein was suggested to be the Nod-factor receptor having structural and, as a consequence, functional differences in Afghan lines and in lines with normal symbiotic specificity (the so-called European lines). The authors identified a candidate gene for the $S y m 2$ role, particularly a previously unknown gene LysM-RLK, named $L y k X$. To date, a number of Sym2 features have been shown in $L y k X$, in particular its allelic states are strictly correlated to the manifestation of Afghan phenotype [52]. But to make a definitive conclusion about the role of $L y k X$, it was necessary to detect this gene mutants and study their phenotype and allelic relationship with Afghan genetic lines. This work was carried out using the TILLING platform provided by the Department of studying plant genomics of the National Institute for Agricultural Research (INRA, France).

The search for mutations was performed within four $L y k X$ fragments of $\sim 400 \mathrm{bp}$. As a result of screening, 20 mutants families were identified, mutations in eight families potentially results in the protein product dysfunction (according to the in silico predictions, program SIFT) [53]. Currently, the test for allelism between individuals carrying mutations in $L y k X$ and Afghan genetic lines is performed, and the results of the test will prove or disprove the hypothesis of $L y k X$ conformity with Sym2.

Thus, in modern science, the study of biological processes is impossible without the study of genes controlling these processes. Despite the advances in molecular genetics and the emergence of high-precision methods of full genome sequencing, the study of mutants is currently one of the major stages of genetic research. The TILLING method combines the advantages of classical chemical mutagenesis and modern approaches to the detection of mutations in a given region, opens up new horizons not only in fundamental biology but also in applied biology, making it possible to discover new alleles of studied genes in any plant species including economically important ones. One of the examples of successful implementation of TILLING strategy is the identification by the authors of a number of mutants of pea gene $L y k X$, for which an important role in establishing nitrogen-fixing symbiosis with rhizobia is assumed.

Despite the seeming simplicity of the method of TILLING, its use is associated with a number of difficulties. The most important step is to create a collection of good quality mutants. In particular, it is necessary to balance between the high frequency of mutations and the survival of mutagenized plants. $\mathrm{M}_{2}$ generation should be sufficiently large to provide the possibility of finding mutations in any gene of interest. Additional difficulties may arise from the species that reproduce mainly vegetatively as well as from the species with a long life cycle. Finally, an important role is played by the possibility of accurate detection of mutations in any analyzed genome portion. One should also remember that some gene mutants cannot be obtained, since mutations in these genes are lethal to the plant.

Thus, the growing interest of researchers, creation of new platforms and development of modifications suggest that the method of TILLING (Targeting Induced Local Lesions in Genomes) proposed about 15 years ago as an alternative to directed mutagenesis, has taken a firm place among the tools of modern molecular biologists and genetics studying plant development, and the scope of its use will be growing in the future. 


\section{REFERENCES}

1. Eise $n$ berg D., M a rcotte E.M., Xenarios I., Ye ates T.O. Protein function in the post-genomic era. Nature, 2000, 405(6788): 823-826 (doi: 10.1038/35015694).

2. Griffiths P.E., Stotz K. Genes in the postgenomic era. Theor. Med. Bioeth., 2006, 27(6): 499-521 (doi: 10.1007/s11017-006-9020-y).

3. $\mathrm{H}$ si a o A., K u o M.D. High-throughput biology in the postgenomic era. J. Vasc. Interv. Radiol., 2009, 20(7 Suppl.): S488-496 (doi: 10.1016/j.jvir.2009.04.040).

4. Mendel' G. Opyty nad rastitel'nymi gibridami /Pod redaktsiei A.E. Gaisinovicha [Experiments on Plant Hybrids. A.E. Gaisinovicha (ed.)]. Moscow, 1965.

5. Lut ova L.A., E zhova T.A., D odu e va I.E., O s i pova M.A. Genetika razvitiya rastenii: dlya biologicheskikh spetsial'nostei universitetov /Pod redaktsiei S.G. Inge-Vechtomova [Genetics of plant development. S.G. Inge-Vechtomova (ed.)]. St. Petersburg, 2010.

6. Inge-Vechtom o v S.G. Genetika s osnovami selektsii [Genetics and the basic breeding principles]. St. Petersburg, 2010.

7. Struhl K. The new yeast genetics. Nature, 1983, 305: 391-397 (doi: 10.1038/305391a0).

8. Reski R. Physcomitrella and Arabidopsis: the David and Goliath of reverse genetics. Trends Plant Sci, 1998, 3(6): 209-210 (doi: 10.1016/S1360-1385(98)01257-6).

9. Al o n s o J.M., E cke r J.R. Moving forward in reverse: genetic technologies to enable genomewide phenomic screens in Arabidopsis. Nat. Rev. Genet., 2006, 7: 524-536 (doi: 10.1038/nrg1893).

10. S m a 11 I. RNAi for revealing and engineering plant gene functions. Curr. Opin. Biotechnol., 2007, 18: 148-153 (doi: 10.1016/j.copbio.2007.01.012).

11. B outros M., Ahringer J. The art and design of genetic screens: RNA interference. Nat. Rev. Genet., 2008, 9: 554-566 (doi: 10.1038/nrg2364).

12. $\mathrm{Hirochika} \mathrm{H}$. Insertional mutagenesis with Tos 17 for functional analysis of rice genes. Breed. Sci., 2010, 60: 486-492 (doi: 10.1270/jsbbs.60.486).

13. B olle C., S c h ne ide $\mathrm{r}$ A., Le iste $\mathrm{r}$ D. Perspectives on systematic analyses of gene function in Arabidopsis thaliana: new tools, topics and trends. Curr. Genomics, 2011, 12(1): 1-14 (doi: 10.2174/138920211794520187).

14. Upadhy y a N.M., Zhu Q.-H., Bhat R.S. Transposon insertional mutagenesis in rice. In: Plant reverse genetics, methods and protocols, methods in molecular biology. A. Pereira (ed.). Springer Science + Business Media, LLC, 2011 (doi: 10.1007/978-1-60761-682-5_12).

15. B arrangou R., Fremaux C., Deveau H., Richards M., Boyaval P., Moin e a S., Ro mero D.A., Horvath P. CRISPR provides acquired resistance against viruses in prokaryotes. Science, 2007, 315(5819): 1709-1712 (doi: 10.1126/science.1138140).

16. Li u L., F a n X.D. CRISPR-Cas system: a powerful tool for genome engineering. Plant Mol. Biol., 2014, 85(3): 209-218 (doi: 10.1007/s11103-014-0188-7).

17. M c Callu m C.M., Comai L., Greene E.A., Henik off S. Targeting Induced Local Lesions IN Genomes (TILLING) for plant functional genomics. Plant Physiol., 2000, 123: 439-442 (doi: 10.1104/pp.123.2.439).

18. Till B.J., Reynolds S.H., Greene E.A., Codomo C.A., Enns L.C., Johnson J.E., B urtne r C., O d d e n A.R., Young K., T a y lor N.E., Henik off J.G., Comai L., $\mathrm{Hen}$ i k off S. Large-scale discovery of induced point mutations with high-throughput TILLING. Genome Res., 2003, 13: 524-530 (doi: 10.1101/gr.977903).

19. Greene E.A., Codomo C.A., Taylor N.E., Henikoff J.G., Till B.J., Reynolds S.H., Enns L.C., Burtner C., Johnson J.E., Odden A.R., Comai L., $\mathrm{Henik}$ off S. Spectrum of chemically induced mutations from a large-scale reverse-genetic screen in Arabidopsis. Genetics, 2003, 164(2): 731-740.

20. Alonso J.M., Stepanova A.N., Leisse T.J., Kim C.J., Chen H., Shinn P., Stevenson D.K., Zimmerman J., Barajas P., Cheuk R., Gadrinab C., Heller C., Jeske A., Koese ma E., Meyers C.C., Parker H., Prednis L., Ansari Y., Choy N., Deen H., Geralt M., Hazari N., Hom E., Karnes M., Mulholland C., Ndubaku R., Schmidt I., Guzman P., Aguilar-Henonin L., Schmid M., Weigel D., Carter D.E., Marchand T., Risseeuw E., Brogde n D., Zeko A., Crosby W.L., B e rry C.C., Ecke r J.R. Genome-wide insertional mutagenesis of Arabidopsis thaliana. Science, 2003, 301: 653-657 (doi: 10.1126/science.1086391).

21. Kurowska M., Daszkowska-Golec A., Gruszka D., Marzec M., Szurma n M., S z a re jko I., M a luszynski M. TILLING - a shortcut in functional genomics. J. Appl. Genet., 2011, 52(4): 371-390 (doi: 10.1007/s13353-011-0061-1).

22. He nik off S., Com a i L. Single-nucleotide mutations for plant functional genomics. Annu. Rev. Plant Biol., 2003, 54: 375-401 (doi: 10.1146/annurev.arplant.54.031902.135009).

23. Tala mè V., Bovina R., S a nguineti M.C., Tuberosa R., Lundqvist U., $\mathrm{S}$ a lvi S. TILLMore, a resource for the discovery of chemically induced mutants in barley. Plant Biotechnol. J., 2008, 6: 477-485 (doi: 10.1111/j.1467-7652.2008.00341.x).

24. Caldwell D.G., McCallum N., Shaw P., Muehlbauer G.J., Marshall D.F., W a u g h R. A structured mutant population for forward and reverse genetics in barley (Hordeum vulgare L.). Plant J., 2004, 40: 143-150 (doi: 10.1111/j.1365-313X.2004.02190.x). 
25. S a d i q M.F., O w a is W.M. Mutagenicity of sodium azide and its metabolite azidoalanine in Drosophila melanogaster. Mutat. Res., 2000, 469: 253-257 (doi: 10.1016/S1383-5718(00)00079-6).

26. Rogers C., Wen J., Che n R., Oldroyd G. Deletion-based reverse genetics in Medicago truncatula. Plant Physiol., 2009, 151: 1077-1086 (doi: 10.1104/pp.109.142919).

27. Li X., Song Y., Century K., Straight S., Ronald P., Dong X., Lassner M., $\mathrm{Z} \mathrm{h}$ a $\mathrm{ng}$ Y. A fast neutron deletion mutagenesis-based reverse genetics system for plants. Plant J., 2001, 27: 235-242 (doi: 10.1046/j.1365-313x.2001.01084.x).

28. Achaz G., Netter P., Coissac E. Study of intrachromosomal duplications among the eukaryote genomes. Mol. Biol. Evol., 2001, 18: 2280-2288 (doi: 10.1093/oxfordjournals.molbev.a003774).

29. J a nder G., B a rth C. Tandem gene arrays: a challenge for functional genomics. Trends Plant Sci., 2007, 12: 203-210 (doi: 10.1016/j.tplants.2007.03.008).

30. Gottwald S., B auer P., Komatsuda T., Lundqvist U., Stein N. TILLING in the two-rowed barley cultivar «Barke» reveals preferred sites of functional diversity in the gene HvHox1. BMC Res. Notes, 2009, 2: 258 (doi: 10.1186/1756-0500-2-258).

31. Perry J.A., Wang T.L., Welham T.J., Gardner S., Pike J.M., Yoshida S., Parniske M. A TILLING reverse genetics tool and a web accessible collection of mutants of the legume Lotus japonicus. Plant Physiol., 2003, 131: 866-871 (doi: 10.1104/pp.102.017384).

32. Stephenson P., B ake r D., Girin T., Perez A., A moah S., King G.J., Øster$\mathrm{g}$ a a d L. A rich TILLING resource for studying gene function in Brassica rapa. BMC Plant Biol., 2010, 10: 62 (doi: 10.1186/1471-2229-10-62).

33. Dalmais M., Schmidt J., Le Signor C., Moussy F., Burstin J., S avois V., Aubert G., Brunaud V., de Oliveira Y., Guichard C., Thompson R., B e nd a hm a ne A. UTILLdb, a Pisum sativum in silico forward and reverse genetics tool. Genome Biol., 2008, 9: R43 (doi: 10.1186/gb-2008-9-2-r43).

34. Till B.J., Cooper J., Tai T.H., Colowit P., Greene E.A., Henikoff S., Co$\mathrm{m}$ a i L. Discovery of chemically induced mutations in rice by TILLING. BMC Plant Biol., 2007, 7: 19 (doi: 10.1186/1471-2229-7-19).

35. Chawade A., Sikora P., Bräutigam M., Larsson M., Vivekanand V., Na$\mathrm{k}$ as h M.A., Che n T., O ls s o n O. Development and characterization of an oat TILLINGpopulation and identification of mutations in lignin and $\beta$-glucan biosynthesis genes. BMC Plant Biol., 2010, 10: 86 (doi: 10.1186/1471-2229-10-86).

36. Himelblau E., Gilchrist E.J., Buono K., Bizzell C., Mentzer L., Vogelzang R., O sborn T., A m a si no R.M., Parkin I.A., Haugh n G.W. Forward and reverse genetics of rapid-cycling Brassica oleracea. Theor. Appl. Genet., 2009, 118: 953-961 (doi: 10.1007/s00122-008-0952-7).

37. Underhill P.A., Jin L., Lin A.A., Mehdi S.Q., Jenkins T., Vollrath D., Davis R.W., Cavalli -S forza L.L., O e f ne r P.J. Detection of numerous Y chromosome biallelic polymorphisms by denaturing high-performance liquid chromatography. Genome Res., 1997, 7(10): 996-1005 (doi: 10.1101/gr.7.10.996).

38. Colbert T., Till B.J., Tompa R., Reynolds S., Steine M.N., Yeung A.T., M c Callum C.M., Comai L., Henik off S. High-throughput screening for induced point mutations. Plant Physiol., 2001, 126: 480-484 (doi: 10.1104/pp.126.2.480).

39. Oleykowski C.A., Bronson Mullins C.R., Godwin A.K., Yeung A.T. Mutation detection using a novel plant endonuclease. Nucl. Acids Res., 1998, 26: 4597-4602 (doi: 10.1093/nar/26.20.4597).

40. Till B.J., Burtner C., Comai L., Henik off S. Mismatch cleavage by single-strand specific nucleases. Nucl. Acids Res., 2004, 32: 2632-2641 (doi: 10.1093/nar/gkh599).

41. Triques K., Sturbois B., Gallais S., Dalmais M., Chauvin S., Clepet C., Aubourg S., Rameau C., Caboche M., Bendahmane A. Characterization of Arabidopsis thaliana mismatch specific endonucleases: application to mutation discovery by TILLING in pea. Plant J., 2007, 51(6): 1116-1125 (doi: 10.1111/j.1365-313X.2007.03201.x).

42. Triques K., Piednoir E., Dalmais M., Schmidt J., Le Signor C., Sharkey M., Caboche M., Sturbois B., Bendahmane A. Mutation detection using ENDO1: application to disease diagnostics in humans and TILLING and Eco-TILLING in plants. BMC Mol. Biol., 2008, 9: 42 (doi: 10.1186/1471-2199-9-42).

43. Minoia S., Petrozza A., D'Onofrio O., Piron F., Mosca G., Sozio G., Cellini F., Bendahmane A., Carriero F. A new mutant genetic resource for tomato crop improvement by TILLING technology. BMC Res. Notes, 2010, 3: 69 (doi: 10.1186/1756-0500-3-69).

44. Niedringhaus T.P., Milanova D., Kerby M.B., Snyder M.P., B arron A.E. Landscape of next-generation sequencing technologies. Anal. Chem., 2011, 83: 4327-4341 (doi: 10.1021/ac2010857).

45. Pareek C.S., S moczynski R., Tretyn A. Sequencing technologies and genome sequencing. J. Appl. Genet., 2011, 52: 413-435 (doi: 10.1007/s13353-011-0057-x).

46. Radutoiu S., Madsen L.H., Madsen E.B., Felle H.H., U mehara Y., Grønlund M., S a to S., N ak a mura Y., Tabat a S., S and al N., S touga ard J. 
"Plant recognition of symbiotic bacteria requires two LysM receptor-like kinases. Nature, 2003, 425: 585-592 (doi: 10.1038/nature02039).

47. Limpens E., Franken C., Smit P., Wille mse J., Bisseling T., Geurts R. LysM domain receptor kinases regulating rhizobial Nod factor-induced infection. Science, 2003, 302(5645): 630-633 (doi: 10.1126/science.1090074).

48. Zhukov V., Radutoiu S., Madsen L.H., Rychagova T., Ovchinnikova E., Borisov A., Tikhonovich I., Stouga ard J. The pea Sym37 receptor kinase gene controls infection-thread initiation and nodule development. Mol. Plant Microbe Interact., 2008, 21(12): 1600-1608 (doi: 10.1094/MPMI-21-12-1600).

49. R a z u movs k y a Z.G. Mikrobiologiya, 1937, 6(3): 321-328.

50. Li e T.A. Temperature-dependent root-nodule formation in pea cv. Iran. Plant Soil, 1971, 34: 751-752 (doi: 10.1007/BF01372829).

51. Kozik A., Geurts R., Heidstra R., Kulikova O., Ellis T.H.N., Bisseling T., La Ru e T., We e d e n N. Detailed map of the sym2 region of pea linkage group I. In: Fine mapping of the sym2 locus of pea linkage group I. PhD thesis. Wageningen University. Wageningen, 1996.

52. Zhukov V.A., Sulima A.S., Porozov Y.B., Borisov A.Y., Tikhonovich I.A. Polymorphism in gene sequence of LysM receptor kinase is associated with Sym2-controlled nodulation in pea (Pisum sativum L.). Proc. $18^{\text {th }}$ Int. Conf. on Nitrogen Fixation. Myazaki, Japan, 2013: 76.

53. S i m N.-L., Kumar P., Hu J., Henik off S., Schneider G., Pauline C. Ng. SIFT web server: predicting effects of amino acid substitutions on proteins. Nucl. Acids Res., 2012, 40(Web Server issue): W452-W457 (doi: 10.1093/nar/gks539). 